\title{
Bacterial avidins are a widely distributed protein family in Actinobacteria, Proteobacteria and Bacteroidetes
}

\author{
Olli H. Laitinen ${ }^{1 \dagger}$, Tanja P. Kuusela ${ }^{1 \dagger}$, Sampo Kukkurainen ${ }^{1 \dagger}$, Anssi Nurminen ${ }^{1}$, Aki Sinkkonen ${ }^{2}$ and \\ Vesa P. Hytönen ${ }^{1,3^{*}}(\mathbb{D}$
}

\begin{abstract}
Background: Avidins are biotin-binding proteins commonly found in the vertebrate eggs. In addition to streptavidin from Streptomyces avidinii, a growing number of avidins have been characterized from divergent bacterial species. However, a systematic research concerning their taxonomy and ecological role has never been done. We performed a search for avidin encoding genes among bacteria using available databases and classified potential avidins according to taxonomy and the ecological niches utilized by host bacteria.
\end{abstract}

Results: Numerous avidin-encoding genes were found in the phyla Actinobacteria and Proteobacteria. The diversity of protein sequences was high and several new variants of genes encoding biotin-binding avidins were found. The living strategies of bacteria hosting avidin encoding genes fall mainly into two categories. Human and animal pathogens were overrepresented among the found bacteria carrying avidin genes. The other widespread category were bacteria that either fix nitrogen or live in root nodules/rhizospheres of plants hosting nitrogen-fixing bacteria.

Conclusions: Bacterial avidins are a taxonomically and ecologically diverse group mainly found in Actinobacteria, Proteobacteria and Bacteroidetes, associated often with plant invasiveness. Avidin encoding genes in plasmids hint that avidins may be horizontally transferred. The current survey may be used as a basis in attempts to understand the ecological significance of biotin-binding capacity.

Keywords: Avidin, Phylogeny, Biotin-binding, Defense protein, Plant invasiveness

\section{Background}

The first known avidin was isolated from the chicken (Gallus gallus) egg white in 1941 [1] as a minor protein component showing extremely high avidity to biotin $\left(\mathrm{K}_{\mathrm{d}}\right.$ $\approx 10^{-15} \mathrm{M}$ ) and is a text-book example of tight proteinligand interaction $[1,2]$. This combined with the avidin's compact tetrameric structure with four biotin-binding

\footnotetext{
*Correspondence: vesa.hytonen@tuni.fi

${ }^{\dagger}$ Olli H. Laitinen, Tanja P. Kuusela and Sampo Kukkurainen contributed equally to this work

${ }^{1}$ Faculty of Medicine and Health Technology, Tampere University, Tampere, Finland

Full list of author information is available at the end of the article
}

sites in each functional protein, and the existing methods to biotinylate a vast variety of biomolecules, has made avidin an important biotechnological tool in protein purification, detection, and assay technologies, but also in diagnostics and pharmaceuticals [3, 4].

The first bacterial avidin, streptavidin, was isolated from antibiotic-secreting Streptomyces avidinii bacteria in 1964 [5]. Since then, several new avidins have been experimentally verified from both eukaryotic and prokaryotic species. Ten avidin family members were identified in the chicken genome between the 1980s and the early 2000s [6, 7], and they were showed to resemble avidin structurally and functionally when expressed as 
recombinant proteins [8, 9]. Further eukaryotic avidins have been found in other avian species, reptiles, amphibians, sea urchin, fish, lancelet and fungi [10-12]. Several putative novel bacterial avidin genes have been detected from bacteria in a wide variety of environmental niches including symbiotic, marine, and pathogenic species. However, none of these bacterial avidins except streptavidin and closely related streptavidin v1 and v2 from Streptomyces venezuelae [13] have been confirmed to be expressed in nature. Avidins are made of beta barrels and their oligomeric state vary from loose dimeric assembly to very stable tetramer.

Avidin has been suggested to have antibiotic qualities, as it renders biotin vitamin unavailable. In oviparous animals, avidins are theorized to protect the eggs from microbes [14]. Evidence that chicken oviductal tissue produces avidin in response to bacterial, viral, and environmental stress supports this hypothesis [14-17]. A recent study revealed that avidin is expressed in avian primary gut epithelial cells along proinflammatory cytokines as acute phase proteins [18]. In line with these findings, two avidin genes, Bjavd 1 and 2 [19] were found to be expressed in lancelet (Branchiostoma japonicum) in response to bacterial and heat shock stress. Interestingly, the Bjavd proteins appeared to recruit macrophages to the site of infection and thus acted as opsonins. While avidin has not been found in plants, transgenic avidinexpressing crops show resistance to insect pests [20, 21] and a correlation between biotin availability and root feeding nematodes was found in legume rhizosphere [22]. In fungi, the tamavidins (Tamavd 1 and Tamavd 2), discovered from the edible mushroom Pleurotus cornucopiae, have been suggested to protect from phytopathogenic fungi [23]. Simultaneously, biotin is essential cofactor avidin expression may cause negative effects. Known eukaryotic avidins are secreted proteins and this could be important factor to avoid the toxic effects. Reflecting the delicate balance in biotin availability, avidin-induced biotin deficiency causes low hatching success and teratogenicity in birds and mice, reflecting the toxic nature of avidin [24]. Silencing of zebavidin expression in zebrafish larvae using morpholinos did not reveal any significant changes in the early development of the fish [25]. Therefore, despite all the efforts, the exact biological role of avidins in various species is not fully understood.

Although avidin genes have been found in several bacterial clades, no comprehensive phylogeny of bacterial avidin sequences has been done. In this study, we present a phylogeny of the bacterial of avidins that were identified by screening Protein Data Bank, GenBank, The European Molecular Biology Laboratory (EMBL) Nucleotide Sequence Database, DNA Data Bank of Japan and UniProtKB databases using verified avidins as query sequences. We identified 946 protein and 213 nucleotide sequences corresponding to new putative avidins. In addition, we identified several new putative avidin clades, each showing their characteristic sequence features. Furthermore, we inspected the genomic and habitational context of the bacterial avidin family. Our results indicate that avidins are widespread among three bacterial phyla, and that the avidin-carrying bacteria inhabit several ecological niches and represent alternative lifestyles. This study reveals avidin family being very rich and proposes that avidin encoding genes are beneficial for bacteria in various environments.

\section{Results}

\section{Avidins exist widely in bacteria}

Queries were run against both protein and nucleotide databases with a set of nine verified avidin sequences. For the protein queries the amount of hits varied between 285 and 303, while for the nucleotide queries the amount of hits varied between 13 and 182. As the pooled query results contained a high amount of redundancy, the previously collected protein and nucleotide sequences were processed to obtain a cleaned-up set of unique 213 nucleotide and 946 protein sequences. This data together with the set of verified avidin sequences was used as a material for later analyses. Based on bacterial species information gathered via BLAST searches, we made a systematic analysis of bacterial genomes, and simplified the list of avidins by selecting representative avidins among groups of identical and highly similar proteins and associated them to representative bacterial species. This group was supplemented in the revision phase with 14 protein sequences, including representing putative avidins from Bacteroidetes. This resulted set of 118 different bacterial species are shown in Additional file 1: Table S1 and their sequences are listed in FASTA format in Additional file 2.

\section{Phylogeny, habitats, lifestyles and ecological significance of avidin harboring bacteria}

Those defined 118 bacterial species with putative avidins belong mainly in phyla Proteobacteria, Actinobacteria and Bacteroidetes with a single hit in phylum Synergistetes. In Actinobacteria, the most of the putative avidins belong to different Streptomyces species whereas in Proteobacteria the species are most often found within Xanthomonas, Rhizobium, Bradyrhizobium, Burkholderia, Legionella, Methylobacterium and Mesorhizobium (Additional file 1: Table S1). Despite coming mainly from two phyla, these new avidinharboring bacteria show varied lifestyles and live in diverse environments. We approached the potential ecological significance of avidins by analyzing the 
lifestyles and environmental niches of those defined 118 avidin gene-carrying bacteria (Fig. 1a). Among this group, we observed many bacteria living in soil (70 species; $59 \%$ of species), while aquatic environments (57 species; $48 \%$ ) were common habitats as well. Significant portion of these bacteria have interactions with either plants or animals. Previous studies have suggested that bacterial avidins may be involved in the competition between species as a part of the defense against other microbes or alternatively, as an agent controlling the root-feeding nematode composition [22]. In the present study avidin-carrying bacteria were often associated with mutualistic lifestyle with plants being either leaf endophytes or found from root nodule rhizosphere but also some plant pathogens causing bacterial canker and blight were identified (Additional file 1: Table S1). Bacterial avidin gene was observed in 36 species (31\%), which are known or predicted human, fungus or plant pathogens. Human or animal pathogens were detected within avidin-carrying bacteria, potentially causing septicemia, pneumonia, melioidosis, pontiac fewer, glanders, cystic fibrosis, Crohn's disease and lymphocytic leukemia (Additional file 1: Table S1). Interestingly, chemolithotrophic lifestyle was also found in Cupriavidus [26]. These results suggest that avidin expression provides advantage for bacteria with diverse lifestyles.

\section{Genomic association of avidin genes with other genes}

We evaluated the genomic association between avidin genes and known biological pathways by inspecting the vicinity of avidin genes within bacterial genomes. This analysis revealed genes with multiple different functions being associated with avidin genes (Additional file 1: Table S2). Interestingly, avidin genes were residing in both plasmids (five identified cases) and in genomes (43 species) of the analyzed bacteria (Fig. 1b). Because $>10 \%$ avidin genes were detected within mobile elements, it is logical that genes responsible for DNA recombination were colocalized with avidin genes (Additional file 1: Table S2). This indicates that plasmid-encoded avidins can be transferred between different bacteria, and maybe even to other life forms too, via horizontal gene transfer. Thirteen bacterial species harbors more than one avidin gene (Fig. 1c), which further supports the importance of avidin for these bacteria. The enrichment analysis showed association with several DNA processing and mobile element GO-terms, which can correlate the plasmid origin of some of the identified avidins. Interestingly, two GOterms statistically significantly associated with avidins included genes from defense pathways (Additional file 1: Table S2).

\section{Avidins falls into eleven phylogenetic clades}

The phylogeny tree of the putative bacterial avidins (Fig. 2a) shows that the avidin family is highly divergent

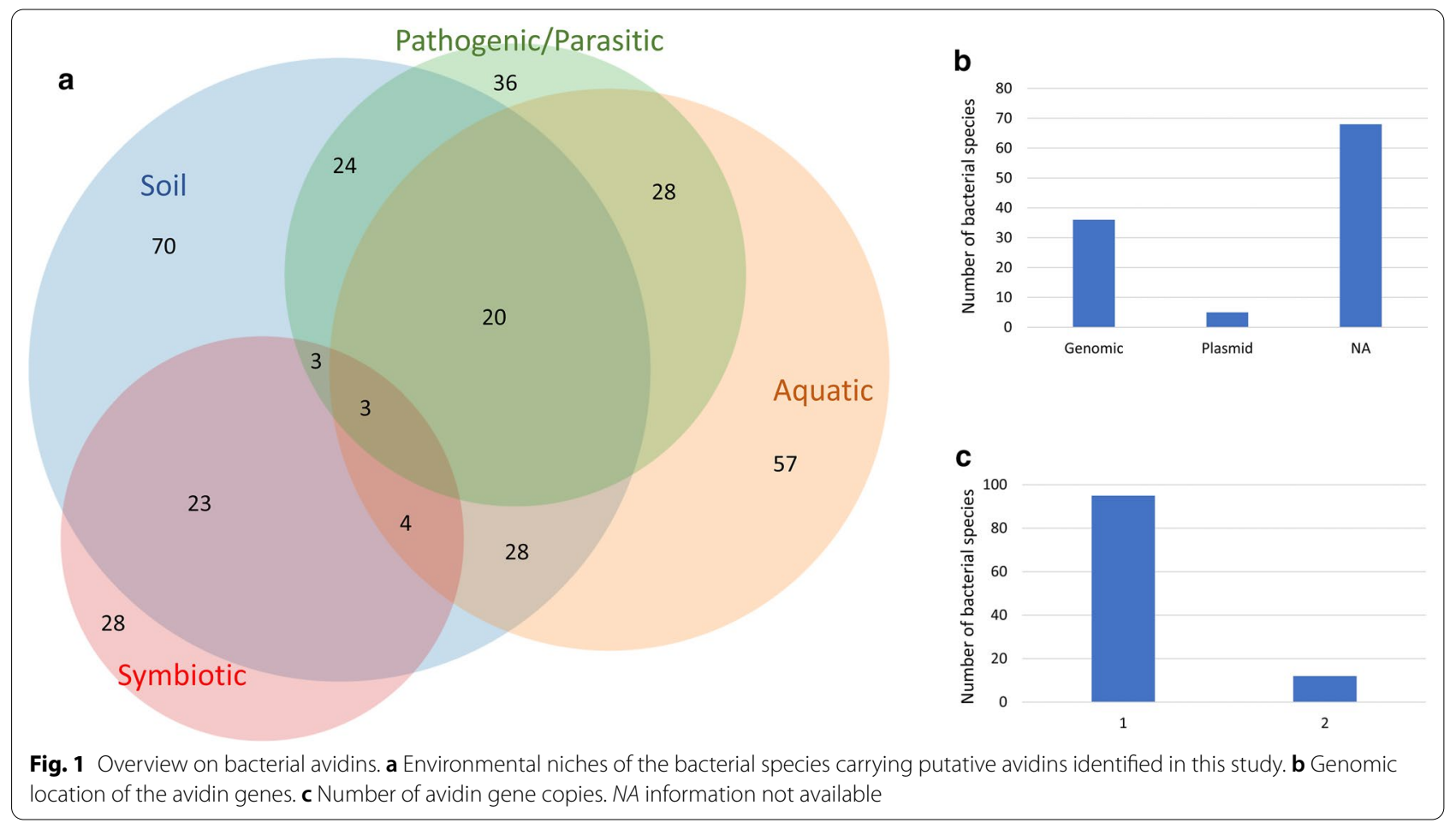



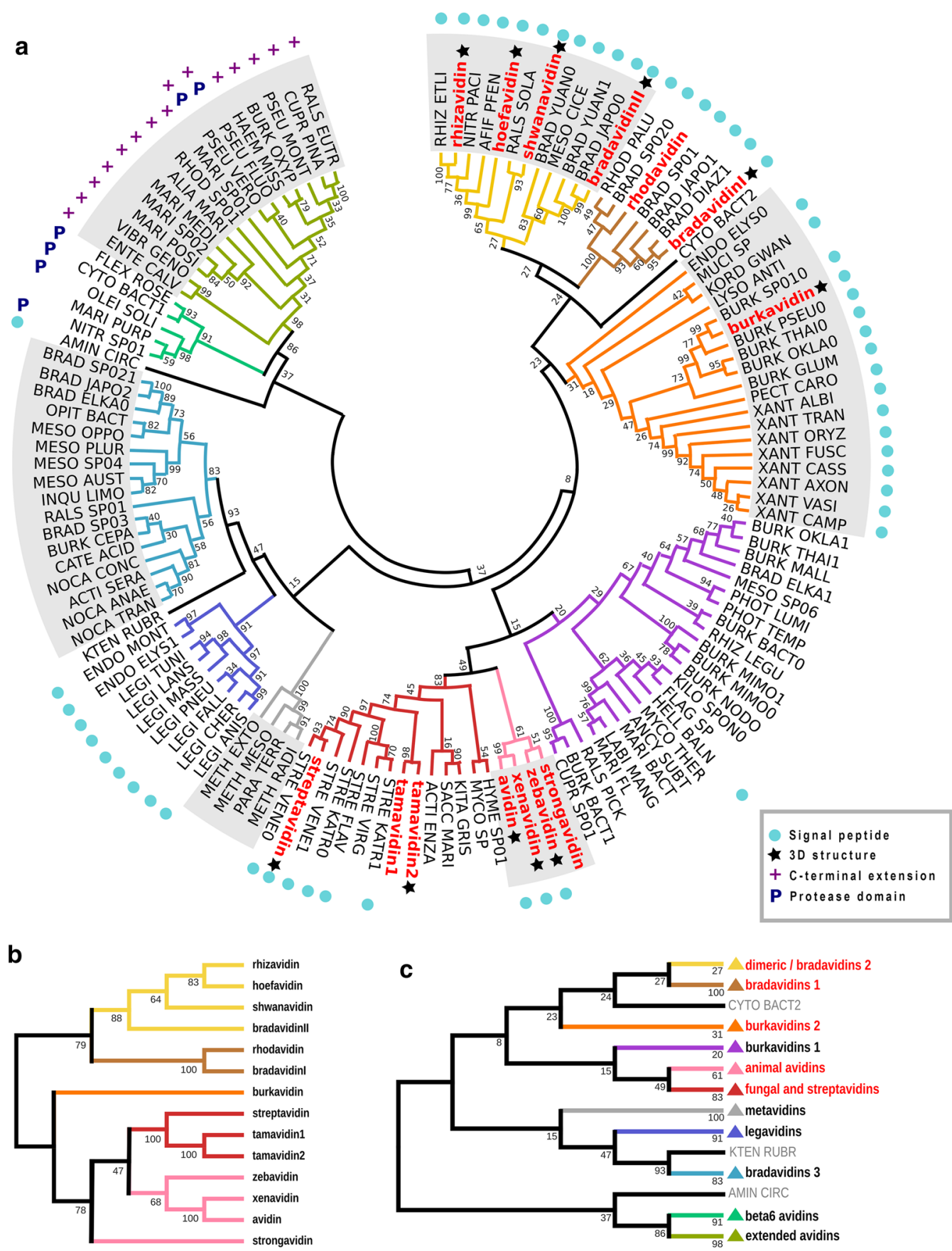

Fig. 2 Phylogenetic analysis of putative bacterial avidins. a Phylogeny tree of the putative bacterial avidins. The verified avidins are shown with bold red font. The avidins with resolved 3D structure are indicated with black star symbol. The avidins containing predicted secretion signal peptide are indicated by cyan spheres. The avidins containing C-terminal extension are indicated by purple plus sign. The avidins containing predicted protease domain fusion are indicated by blue P letter. The bacterial avidins are grouped into 11 branches indicated with colors. $\mathbf{b}$ Phylogenetic cladogram tree of functionally verified avidins, colored according to $\mathbf{a}$. $\mathbf{c}$ Phylogenetic cladogram tree of the verified and putative bacterial avidin sequences with collapsed subgroups. Triangle marks the collapsed clade, red text the clades containing verified avidins, and grey text that the indicated sequence was an outlier. The two outlier species, Aminiphilus circumscriptus and Rhodonobacter sp. OR444, were isolated from waste sludge and heavy metal polluted soil respectively 
with 11 separate clades potentially representing structurally and functionally divergent avidin groups. For example, verified dimeric avidins (such as rhizavidin [27]) and avidins with ambivalent quaternary structure (such as bradavidin2, which appears to have a dynamic (transient) oligomeric state in solution depending on concentration [28]) clustered together into a clearly defined clade (Fig. 2a).

In order to evaluate the putative avidin sequence alignment and phylogeny tree, we also built a restricted phylogeny tree consisting only of the verified avidins (Fig. 2b). Several of the distinct clades within the comprehensive phylogeny (Fig. 2a) did not cluster together with clades containing verified avidin sequences, indicating that they potentially represent completely new avidin types (Fig. 2c). Avidins reported to have fungal origin, tamavidin 1 and tamavidin 2, clustered together with the rather well-defined clade of streptavidins. Meanwhile, the rest of the verified eukaryotic avidins formed a clade together. In this context, it should be noted that there would be a significant number of avidins in the genomes of eukaryotic species, not covered in this study.

Strongavidin was the only verified avidin that changed its position topologically, when the comprehensive phylogeny and the verified avidins' phylogeny was compared. In the former, the strongavidin clustered together with avidins originating from animal species, meanwhile in the latter, it formed its own outgroup of the cluster including both streptavidins and eukaryotic avidins.

\section{Structure-function evaluation of the putative avidins}

Avidin proteins are well-characterized structurally (Fig. 3a-d) and the functional role of the residues lining the ligand-binding site as well as residues within the subunit interfaces have been extensively studied in previously reported research, as reviewed by Laitinen et al. [3, 29]. Here, we present a structure-based multiple sequence alignment of the verified avidins (Fig. 3e), which could be used as a reference when inspecting the putative avidins. For example, there are a number of aromatic residues strongly conserved within putative avidins which have been found to be functionally important in previous studies [30-33]. Interestingly, only few positions remain completely conserved, when the whole landscape of the putative bacterial avidins is inspected using the sequence logo method (Fig. 3f). The first beta strand and the turn between the strands 1 and 2 shows higher conservation than the rest of the beta strands (Fig. 3f). The glycine residues within the strands 1,2,3, 4, and 6 are well conserved as are also the aromatic positions across the whole avidin sequence (Fig. 3f). These most likely reflect the strongly conserved beta-barrel structure of the avidin (Fig. 3a, d), having ligand-binding site lined up with aromatic residues in the middle of the barrel (Fig. 3c).

\section{Aspartic peptidase identified as a terminal fusion of Extended clade avidins}

Domain homology analysis with InterPro [34] detected a putative aspartic peptidase A1 family domain $\mathrm{N}$-terminally of the putative avidin domain in two "Extended" clade pseudomonas sequences (P. fluorescens and P. veronii) and in Oleiagrimonas soli, Cytophagales bacterium 1 and Nitrincola nitratireducens of the $\beta 6$ clade (Fig. 4, Additional file 1: Table S3). In Flexibacter roseolus ( $\beta 6$ clade) an aspartic peptidase A1 family domain was predicted C-terminally of the putative avidin domain (Fig. 4). Aspartic peptidase A1 family, or pepsin-like aspartyl peptidases, are bilobed endopeptidases that have been previously found in bacteria [35]; we are however not aware of avidins having been previously reported to be connected to bacterial aspartic endopeptidases. Shorter $(\sim 150$ residues) C-terminal extensions were found in several species in the "extended" subgroup: Enterovibrio calviensis, Pseudomonas monteilii, Haematobacter missouriensis, chemolithotrophs Cupriavidus pinatuboensis and C. necator (formerly Ralstonia eutropha), Rhodanobacter sp. (outlier grouped together with extended and 36), Aliagarivorans marinus, as well as Marinomonas posidonica, M. mediterranea and Marinomonas sp. MWYL1. The shorter extension appeared to be partial in Burkholderia oxyphila and Maricaulis sp. The shorter extensions were somewhat conserved (not shown), but InterPro and NCBI Conserved Domains Database search failed to identify conserved domains in the region.

\section{Plant-associated bacterial avidins}

Based on our survey, several taxonomically distant Leguminous plant species host bacteria having genes encoding avidins. The species include significant agricultural plants species like common bean, soybean and peanut (Table 1). The other set consists of species with invasive characteristics outside their native areas. Sinkkonen et al. [22] have previously proposed that Leguminous plants benefit from the biotin-binding characteristics of their avidinproducing root symbionts. A probable reason is that these provide protection against root herbivory [22]. Our observation of the geographic distribution of crop and non-invasive wild plants with unintentionally sequenced bacterial avidins further supports this hypothesis.

\section{Bacterial avidins in aquatic environments}

With a single exception, bacteria carrying putative avidins found within Bacteroidetes belonged to species characterized in aquatic environments (Additional file 1: Table S1). Ancylomarina and Labilibaculum are genera 


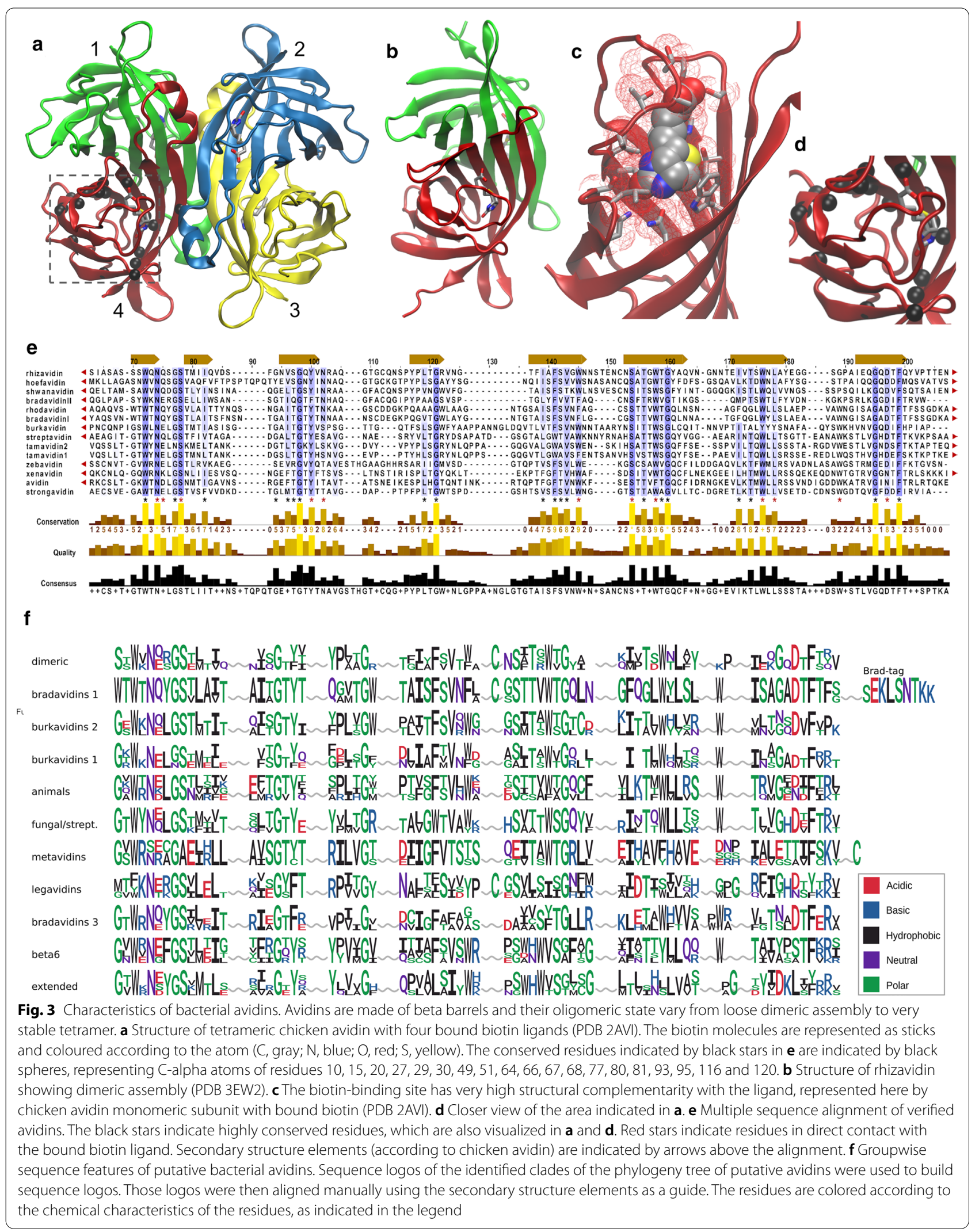




\begin{abstract}
(See figure on next page.)
Fig. 4 Bacterial avidins may be expressed as fusion proteins together with a pepsin-like aspartyl protease. a Multiple sequence alignment of the putative aspartyl protease domain of bacterial avidin sequences with the aspartyl proteases pepsin (Sus scrofa, PDB ID: 4PEP, [75]), cathepsin D (Camelus dromedarius, PDB ID: 4AA9, [82]) and chymosin (Ixodes ricinus, PDB ID: 5N71, [83]). The aspartic acid (asparagine in cathepsin D) residues of the putative active site are highlighted with red arrowheads [84]. $\mathbf{b}$ Multiple sequence alignment of the putative avidin domain of bacterial avidin sequences with streptavidin (Streptomyces avidinii, PDB ID: 3RY2, [76]), chicken avidin (Gallus gallus, PDB ID: 1VYO, [85]) and rhizavidin (Rhizobium etli, PDB ID: 3EW1, [53]). Multiple sequence alignment of the putative avidin domain of bacterial avidin sequences with streptavidin, chicken avidin and Xenopus avidin (xenavidin). Both alignments were carried out with T-Coffee in the Expresso mode (http://tcoffee.crg.cat/; [70, 80, 81]). c Schematic picture showing the domain organization of the putative protease-avidin fusion proteins. $\mathbf{d}$ Homology model of Oleiagrimonas soli protease-avidin fusion protein, generated with Modeller 9.25 [74]. Swine pepsin (PDB ID: 4PEP; [75]) was used as a template for the protease domain, and streptavidin (PDB ID: 3RY2; [76]) for the avidin domain. The active site aspartic acid residues are shown in red
\end{abstract}

present in anoxic coastal sediments and in anoxic waters of salt marshes and the Black Sea [36-40]. Aquimarina is a genus containing aquatic bacteria widely observed in salty waters [41]. Flagellimonas are freely moving bacteria found mainly in marine environments [42], and Flexibacter roseolus was isolated from a hot spring [43]. The sole known species of Ekhidna forms colonies on marine agar [44], and Kordia periserrulae was isolated in a digestive tract of a marine Eukaryote [45]. Today, genera Fabibacter and Marinifilum contain only marine organisms [46, 47]. Hypothetically, the ability to produce avidins might reduce browsing by predators of many of these easily harvestable organisms. Alternatively, in case of Aquimarina, Ekhidna and Fabibacter, avidin production might enhance pathogenesis; the genera are known to grow on aquatic Eukaryotes. Other taxa in Bacteroidetes were characterized at a taxonomically broad level. In addition to marine and aquatic species, hits within Bacteroidetes contained individual bacterial species from terrestrial ecosystems [48].

\section{Discussion}

The first members of avidin protein family were isolated from very different life forms i. e. eukaryotic egg-laying bird, chicken, and soil living prokaryotic bacteria Streptomyces avidinii $[1,5]$. Although the functional properties as well as quaternary and tertiary structures of these two proteins are well conserved [29], the low primary structure similarity $(\approx 30 \%)$ raised a question if they have a common ancestor or if they have developed independently. While the catalogue of avidins has rapidly expanded, the observed sequence diversity has remained high. The same observation concerns the putative avidins characterized in this work. The overall sequence identity or similarity of the identified new avidins (Additional file 1: Table S4) reside in the twilight zone between major clades, which challenged the generation of high-quality alignment and phylogenetic tree. This suggests that if all identified avidins share a common ancestor, the avidin protein has a long evolutionary history.

Phylogenetic characterization of verified and putative avidins (Fig. 2) indicate that the known experimentally verified avidins are distributed along several different clades of the phylogeny tree. The previously characterized avidins belong to the clades of Dimeric avidins, Bradavidins1, Burkavidins2, Fungal and streptavidins and animal avidins. Additionally, completely new clades with a number of putative avidins were identified. Do those novel clades represent functional avidins? This question can be addressed by inspecting the conservation of well-known functional amino acid residues, which has been visualized using sequence logos of the phylogenetic clades in Fig. 3f. In a general level, the new avidins in these clades seem to be biotin binders, although some Burkavidins2 clade members contain several conservative and some non-conservative substitutions in positions with high conservation among verified avidins.

Fibropellins offer an interesting reference for the prediction of the biotin-binding activity of the putative avidins, as fibropellins do not bind biotin [49]. We have previously shown that by simultaneous mutation of only two biotin-binding residues of chicken avidin according to fibropellin template, i.e. substitution Trp110 with Lys and Trp70 with Arg, was enough to virtually demolish the avidin's biotin-binding activity [31]. This indicates that one effective way to reduce biotin-binding capacity is a substitution of hydrophobic ligand-binding residues with bulky charged ones. Another way to lead to lower biotin binding is to replace residues forming hydrogen bonds with biotin by small hydrophobic residues or to introduce bulky residues to fill the biotin-binding pocket $[29,50]$.

Out of the new avidin groups, Burkavidins1 have considerably high number of non-conservative substitutions in their biotin-binding residues, but none of those hit the key aromatic residues and others also seem to be benign, supporting the possibility that they are true biotin binders. One of the $\beta 6$ avidins members, i.e. Flex rose avidin (Flexibacter roseolus, Additional file 1: Table S1), lacks the whole $\beta$-sheet 1 and the following three hydrogen bond -forming biotin-binding residues residing in Loop 1 within the confirmed avidins. Other two $\beta 6$ avidin members contain these residues and all three show considerably well conservation within the other biotin-binding 
a

Flexibacter_roseolus Cytophagales_bacterium Nitrincola_sp._AK23 Pseudomonas fluorescen Pseudomonas_veronii pepsin chymosin

cathepsin_

Flexibacter_roseolus Cytophagales_bacterium Nitrincola_sp._AK23 Pseudomonas fluorescen Pseudomonas_veronii pepsin chymosin

Flexibacter_roseolus Cytophagales bacterium Nitrincola_sp. AK23 Oleiagrimonas_soli Pseudomonas_fluorescens Pseudomonas_veronii pepsin

chymosin

Flexibacter_roseolus Cytophagales bacterium Nitrincola_sp._AK23 Oleiagrimonas_soli Pseudomonas_fluorescens Pseudomonas_veronii pepsin

(a)

Flexibacter_roseolus Nitrincola_sp. AK23 Oleiagrimonas_soli Pseudomonas_fluorescens Pseudomonas_veronii pepsin

chymosin

b

Flexibacter_roseolus Nitrincola_sp._AK23 Oleiagrimonas_soli Pseudomonas fluorescens Pseudomonas_veronii chicken_avidin rhizavidin

streptavidi

Flexibacter_roseolus Cytophagales bacterium Nitrincola sD. AK23 Oleiagrimonas soli Pseudomonas fluorescens Pseudomonas_veronii chicken_avidin rhizavidin

c

Nitrincola sp. AK2

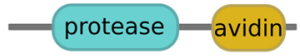

Oleiagrimonas soli

Pseudomonas fluorescens

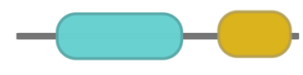

Pseudomonas veroni

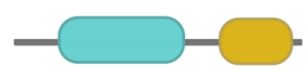

Flexibacter roseolus

Cytophagales bact.
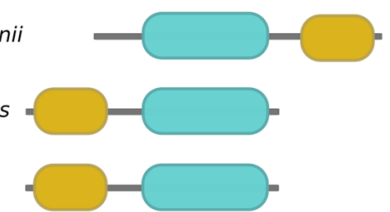

141 AFGLQMG - . - SLSDNGATPWYAQIGLGTPAQDLKFMLDTGTDNTWITSTACTTAACLA - - HNRYNPQASSTFKVIDPN 213 24 EFTLTRG -... VLTDNGATPWTTTIGVGTPPQPLRIMLDTGTVNTWVTASS CTTEACRL - HTAFNPEASTTFVGRQA 96 11 TI TMQRG . . . PFQNNGATPWYTLVPVGTPGQLLKLSLDTGTN I TWI TS TLCSPERCQHYS AGRFDYQASSSFTFTDCL 85

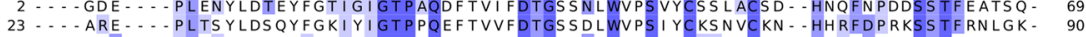
Y 97 PTS VS FGPWGS MGVVMGNDVCHLNY - EHAGQRS LVPFTEPMS LYLAVS YEGQQFSELDCDGGFAI PS I . - PC - OQPSAL 171

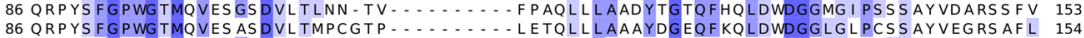
70 ELS I TYGT - GS MTG I LGYDTVQVGG I SD.......... TNQ I FGLSETEPGSFLYYAPFDG I LGLAYPS ISA.SGATPV 13 91 PLS I HYGT-GSMEGFLGYTVTVSNIVD. - . PNQTVGLSTEQPGEVFTYSEFDGILGLAYPSLAS-EYSVPV 157 293 MIQLYKDAKIS Y - - LCASFY - - TNKAEQL - GECLFGGIDIDKFN INTLQWLSL - - KQVQTVGLEYLWDIQLTNFLVN - - 362 298 LLQLMADGKIDF - - AVASFW- - FNNAAGY - GECLFGAIDYTKFEPSS LRGYTL - - EAVTISGLEYLWGIKLTNFLVN - - 367 172 LEELKNQGLI RH - - A I ASFW- - FDPVRGE - GRCLLGALDQTLYEPTS VNCLAL - - KPLE - GELGYLWS VCLDQLQIG - - 240

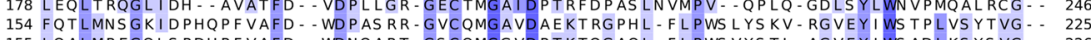
155 LQALMREGQ LSPDHPF VAFD - - WDNQART - GS CQMGGVDPTKTQGAQL - FLPWS VYSTL - AGVEYI WS ADLKS YSVG - - 226

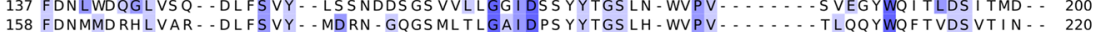

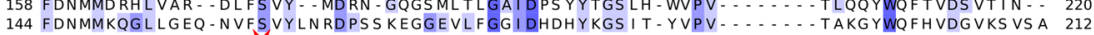

363 -.. GFPVQ-AGI TDFVLDTGSSYFKGPQDLIQILINAVTY-NGELPTYVTS ESALSQYPTIGLQIGSQTYYLQPQDYFL 436 368 - - NLPVQ-AGI TSFI LDTGSS I FKANQQI I DTLLNAVTL - QGQLPI TISDPNLMANYPTITLNFSNNLYQLTPQQYFI 441

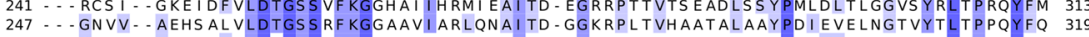
226 - . GDVL - ARNVTFALDSGSSQFKGDDRLMRQTLERIAQ - GGS …… . . . PEVVLGFADGEITLGPNLYNV 284 $227 \ldots$... SELM - ASN I KFALDSGSS QFKGDDGLMRRTLARIAQ - GGE .......... 221 ... GVAVACVGGCQAI LDTGTS VLFGPSSDILKIQMAIGATENRYGEDVNCGN LRSMPTVVFEINGRDYPLSPSAYTS 290 442 - QLSSNSWTIGIQTL D DG. - MPEGMLLVGSVFLETVYS IFDFENK . . . . . . . . . . . . MIGLATL.

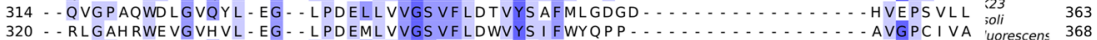
285 L IEEGPEQGKTLPQFEPLG - - M-ADLVLVGSLVMEYCYTVYEYRVVQCRPGAYSLAPVGVWLFNRPEGPQI IS eronii 354 277 - QDD - DSCTSGFEGM - DVPTSSGELWI LGDVFIRQYYTVFDRANN ………… KVGLAPVA

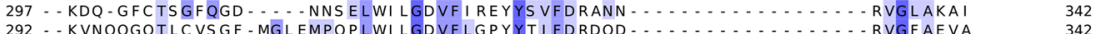

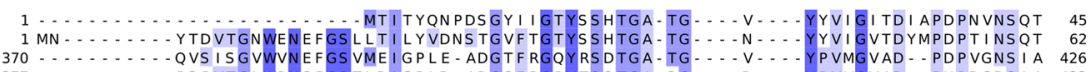

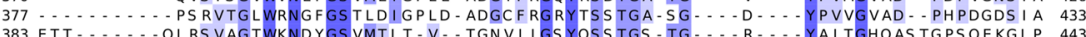

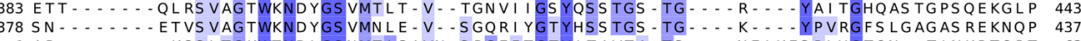

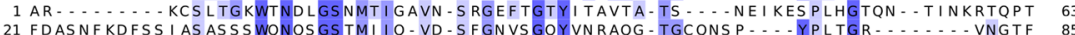
13 A ……. . EAGITGTWYNQLGSTFIVT - AG - ADGALTGTYESAVGNAES … - . . . . YVLTGRYDSAPATDGSGTA

46 VAFS VS WRNTVG - PTES -.. GANWVS AFAGQVQVQADGS LAI ATTYLLQE - NTNP - ADNW-SSTI VAPS TFRKIS - D - . 114 63 ISFS VS WRS YSS - PPTPPQEGDNWVSGFAGQLQ INPDGSEQ I VTTYLLQK - NSNP. ADNW-GATVVATATFKRSN - ALPK 137 434 IS FAVS WRS LVG - KPDP - . - SWHWVS GFTGLLQRK - DGVDQI ATTYLLQQ - NADAQTPDW-MATAIYPSTFVR I G ..... 501

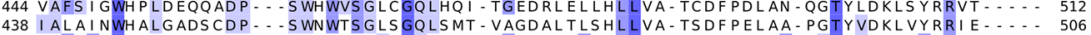
64 FGFTVNWKFSES........... TTVFTGQCF I DRNGKEVLKTMWLLRS - S VND I GDDW-KATRVGINIFTRLR - T - Q - 12

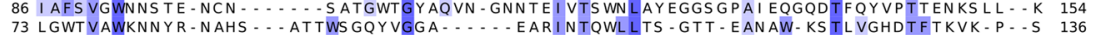

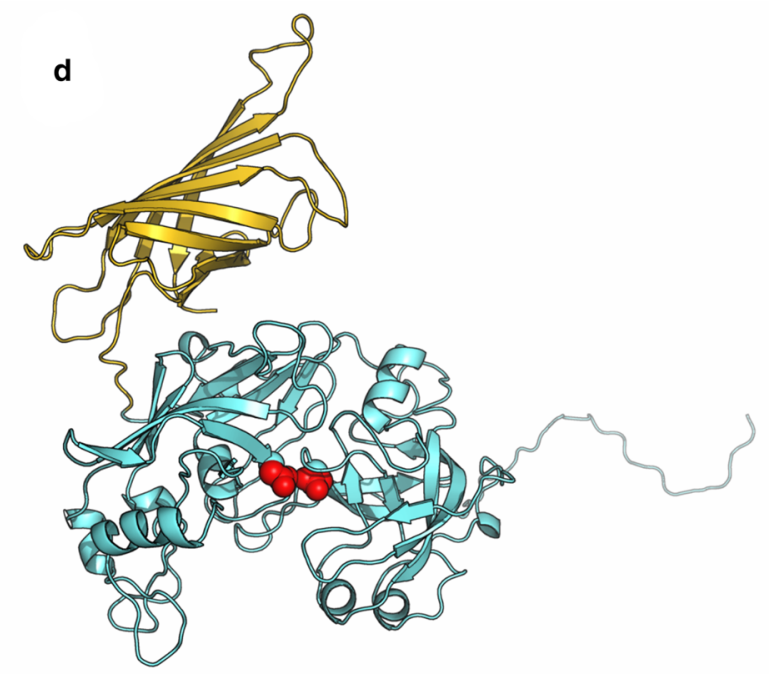


Table 1 The economic significance and native distribution of plants known to host nitrogen-fixing root nodule bacteria with verified avidin production

\begin{tabular}{llll}
\hline Bacterial species & Plant species & Economic significance & Native distribution \\
\hline Bradyrhizobium arachidis & Peanut & Crop plant & Southern America \\
B. diazoefficiens & Soybean & Crop plant & East Asia \\
B. elkanii & Green bean, soybean & Crop plant & South America, East Asia \\
B. japonicum & Soybean & Crop plant & East Asia \\
B. pachyrhizi & Mexican yam bean & Crop plant & Central America \\
B. sp. WSM2793 & Rhynchosia totta & Native vine & Southern Africa \\
B. sp. WSM3983 & Coral vine & Native vine & West and South-West Australia \\
B. sp. WSM4349 & California broom & Native bush & California \\
Burkholderia cepacia & Yellow lupine & Crop plant & Eastern Mediterranean area \\
\hline
\end{tabular}

residues. Therefore, it is possible that the polypeptide segment in the case of Flex rose avidin is missing due to sequencing error and all three members of this clade are true avidins with retained biotin-binding capacity. In contrast, Metavidins show the most numerous nonconservative changes in their respective biotin-binding residues, questioning their ability to bind biotin. Other new avidins in clades Legavidins, Bradavidins3 and extended avidins all look potent biotin binders. However, as learned from fibropellins, it is not easy to predict a degree of changes in biotin-binding residues to reliably judge, which of these new putative avidins really bind biotin without biochemical characterization. Also, interface residues, which define the strength and the presence of oligomeric assembly have effects on the ligand binding characteristics $[31,51,52]$.

Overall, the sequence analysis of the putative and verified avidins reveals that there are only few highly conserved residues along the whole sequence, while some positions are semi-conserved. We used known structure of chicken avidin to inspect the location of the conserved residues, which are not directly linked to biotin binding (Fig. 3a, d). This analysis indicates that significant portion $(>10)$ of the conserved residues are located in the interface between subunits 1 and 4 while only one of them (Gly116 in the case of chicken avidin), is contributing to the interface between subunits 1 and 2. This suggests that the interactions supporting 1-4 dimer, analogous to those observed, for example, in rhizavidin [53], are more conserved within bacterial avidins than the interactions maintaining the tetrameric assembly observed in avidins from eukaryotic origin and in streptavidin.

Without experimental work, it is impossible to judge the functional nature of the novel avidin clades. As opposed to the high structural similarity of founding members of the avidin family, chicken avidin and streptavidin, the previous experimental work has revealed, that the avidin family is rather divergent in terms of structural details. For example, rhizavidin and hoefavidin $[53,54]$ utilize unique structural solution to build the tight biotin binding and this enables high biotin-binding affinity without contribution from the neighboring subunit, which appears absolutely necessary for the high biotinbinding affinity in the case of chicken avidin and streptavidin [31, 32]. The more thorough examination and discussion is found in the master's thesis work by Tanja Kuusela (https://tampub.uta.fi/handle/10024/102386).

Avidins have not identified so far to contain other parts having functions on their own. Streptavidin has a C-terminal extension in its protein sequence, but it is cleaved in the mature form of the protein. Bradavidin has a C-terminal extension functioning as an intrinsic ligand [55] and biotin-binding protein $\mathrm{B}$ has a predicted C-terminal alpha-helix with no known function [6]. In this regard, the aspartic peptidase domain recognized in extended avidins is a novel finding that may be connected to avidin's defence function.

Previous studies with birds suggest that oviparous vertebrates utilize avidins to fight against pathogenic organisms. For example, avidin expression has been induced with bacterial and virus infection in chicken $[16,17]$. It is possible, that bacteria also utilize avidins to compete with other organisms and this has significance in bacterial pathogenesis. This is supported with the fact that streptavidin was originally identified as secreted antibiotic factor [5]. Our present study reveals that several common human pathogens carry genes encoding putative avidins. This raises a question whether biotin binding leads to more efficient invasion of host tissues due to reduced anti-inflammatory activity by eukaryotic, multicellular host organisms. Indeed, the life strategy of several human, fungal and plant pathogens seems to include potential for biotin binding (Fig. 1 and Additional file 1: Table S1). 
Another evolutionary reason for avidin production in pathogenic bacteria may be that biotin binding helps to outcompete other micro-organisms utilizing the same host or anatomic site, such as wound or enteral surface. Significant portion of the identified putative avidins ( $\sim 50 \%$, Fig. 2a) contain signal peptide for secretion, which would enable to avoid toxicity for the host cell. Finally, as several pathogens utilize also decaying tissues, avidins may protect from predation by microscopic multicellular organisms, such as nematodes [22].

Evaluation of plant association of bacterial avidins revealed several invasive plant species. Exotic leguminous invaders that host Bradyrhizobium spp. or Burkholderia spp. are a world-wide problem: Alien Lupinus spp. are serious exotic weeds in Europe, Australia and South America [56], http://www.NOBANIS.org), Australian Acacias are serious invaders in other parts of the world [57, 58], European Scotch broom (Cytisus scoparius L.) has formed large monocultures in Eastern Australia, New Zealand and North America [59], and South American Mimosa pigra L. has outcompeted natural vegetation in many ecosystems at other continents [60]. Main root symbionts of M. pigra are Burkholderia spp. [61], while Bradyrhizobium and other Rhizobiales prevail in the other invasive genera in novel geographic environments [56, 62]. In Australia, nitrogen fixing symbionts of $M$. pigra have a broader host range and a distant genetic relationship to strains isolated within the species' indigenous region in South America [63]. Similarly, invasive Fabaceous aliens in New Zealand are nodulated by Bradyrhizobium species, while native legumes host a diverse nodulating bacterial fauna but not Bradyrhizobium sp. [64]. All these exotic leguminous species host bacteria that have been connected to the production of biotin-binding bacterial avidins. The findings lend support to the hypothesis by Sinkkonen et al. [22] that legumes may turn out to become invasive species outside their native region as they host bacteria producing biotin-binding compounds.

This study identified putative bacterial avidins as taxonomically and ecologically diverse group mainly found in Actinobacteria, Proteobacteria and Bacteroidetes. Because we had only limited number of experimentally verified avidins available, the obtained species coverage may evolve once more sequencing and proteomics data is available and when novel avidins have been functionally verified.

We identified that avidin genes are often localized in mobile genetic elements. Proposing avidins to function as defensive tools within bacteria closes the circle: Streptavidin was originally detected as antimicrobial agent secreted by Streptomyces avidinii [5]. We therefore postulate that avidins are widely distributed within bacteria and are functionally important tools for bacteria to defend their environmental niche, invade into other organisms, cause pathogenicity and help plants to invade. It is 80 years since the identification of chicken avidin but the story of avidins seems just to begin.

\section{Conclusions}

Avidins are likely an old protein family and show high divergence across the bacteria. In general, avidins appear to be carried out by bacteria that inhabit niches in close intimacy of other bacteria, animals, fungi and/or plants. However, this could reflect bias from human interest, as these kinds of species are often research targets for their importance as beneficial, parasitic or pathogenic agents.

Apparently, there are only few strictly conserved features defining avidin, instead the different avidins seem to share approximately the same number of features from the pool of important sequence characteristics. The genomic context of avidin suggests importance for the bacteria, as the avidin gene was present on the primary chromosome more often than in secondary replicons. However, no clear association with genes of distinctive biological processes and pathways were present.

\section{Methods}

\section{Database searches to identify novel bacterial avidin sequences and sequence processing}

Nine verified avidin sequences: streptavidin (UniProtKB: P22629); bradavidin I (Q89IH6); bradavidin II (Q89U61); rhizavidin (Q8KKW2); shwanavidin (Q12QS6); avidin (P02701); zebavidin (E7F650); xenavidin (A7YYL1); and tamavidin 1 (B9A0T6), were used as the query sequences using the domain enhanced lookup time accelerated basic local alignment search tool (DELTA-BLAST) algorithm. Non-redundant protein databases were used as a search set including RefSeq, Protein Data Bank (PDB), GenBank, and UniProtKB [65]. The search was limited to bacteria and the maximum target sequence limit was set to 5000 with BLOSUM62 as the scoring matrix, and the parameters were set to adjust for short input sequence. The query was further refined with PSI-BLAST algorithm with E-value cut-off of 0.01 and required identity greater than 19\% [66]. Nucleotide sequences were searched for with tBLASTn algorithm limited to bacteria against all non-redundant databases including Genbank, The European Molecular Biology Laboratory (EMBL) Nucleotide Sequence Database, and DNA Data Bank of Japan (DDBJ) [67-69] with the same search parameters as with protein queries. Duplicate sequences were removed with Python (3.4) language's Biopython package and 
sequences corresponding to synthetic proteins or modified organisms were removed. All protein sequences were inspected to retrieve the original genomic features and their full nucleotide sequences. Similarly, the genomic position for each nucleotide sequence was obtained from genome tBLASTn and the partial DNA sequences were replaced with a previously annotated full cDNA feature, if such was present. The nucleotide sequences shorter than 300 bp were also extended from the genomic context if possible. Those nucleotide sequences that did not yet have a corresponding protein sequence were translated and added to the protein set. The list of 118 avidins used in the detailed analyses are provided in FASTA format in Additional file 2.

\section{Multiple sequence alignment}

Two multiple sequence alignments (MSA) were constructed from the two different sequence sets. Structural MSA used the set of verified avidins, while a more comprehensive MSA was built upon the larger set of the putative avidins identified in this study. The structural MSA was constructed from the set of 14 verified avidins with T-Coffee in Expresso-mode [70]. The structures in the structural MSA construction were 1vyo for AVD, 4dne for Streptavd, 2y32 for Bradavd I and Rhodavd, 4ggz for Bradavd II, 3ew2 for Rhizavd, 3szj for Shwanavd, 4z6j for Hoefavd, 2uz2 for Xenavd, 4bj8 for Zebavd, 2fhl for Strongavd, 2szc for Tamavd 1 and Tamavd 2. MSA was cleaned up manually with AliView [71] by removing gaps from the unaligned $\mathrm{N}$ - and $\mathrm{C}$-terminal termini. The alignment of the putative avidin sequences was constructed using the structural MSA of verified avidins as seed alignment with MUltiple Sequence Comparison by Log-Expectation (MUSCLE; [72]) to align the putative avidins against the profile of verified avidins. The set of putative avidin sequences was refined iteratively after aligning the full set by removing the short or highly similar sequences as well as highly variable sequences. This MSA was inspected with AliView and the gaps close to sequence termini were removed and the positions of biotin-binding and conserved AA homologues were used to adjust the MSA. The alignments were visualized using Jalview 2.

\section{Phylogenetic analyses}

Phylogenetic analysis was performed in MEGA6.0 using the structural and full MSA, respectively [73]. The maximum likelihood (ML) algorithm was used with following parameters: Jones-Taylor-Thornton (JTT) model adjusted for site-specific AA sequences as the substitution model and the phylogeny quality was tested with bootstrapping (BTSP) with 300 replications, rates among sites were set gamma distributed with invariant sites, gaps or missing data was handled with partial deletion while site coverage cut-off was set to $95 \%$, branch swap filter was strong, and ML heuristic method used the Nearest-Neighbour-Interchange (NNI) with initial tree calculated with the default neighbour-joining (NJ) method.

\section{Enrichment analysis}

The following bacterial genomes, representing different sub-branches of the phylogenetic cladogram trees, were chosen to be assessed in enrichment analysis: Bradyrhizobium diazoefficiens (BA000040, GenBank), Ralstonia eutropha (CP000090-93), Rhizobium etli (CP00107477), Methylobacterium extorquens (CP001298-1300), Catenulispora acidiphila (CP001700), M. mediterranea (CP002583), Ralstonia pickettii (CP00667-69), Legionella pneumophila (CR628336-38), and Xanthomonas fuscans (FO681494-97) [68]. The genomic features from these organisms and their assemblies were pooled together, and avidin (putative or verified) gene's vicinity was defined as 500 bp upstream and downstream from the gene's termini. Gene Ontology (GO-terms) were searched for each feature. If the feature was not annotated to any GO-term, the annotations for PFAM, IPR, or TGRFAM terms were mapped to corresponding GO-terms. Fischer's exact test was performed to evaluate, if features annotated to a certain GO-term clustered significantly more often with avidin gene than expected by random distribution. Biopython was used for the processing and analysing the data.

\section{Visualization}

The 3D structures obtained from Protein Data Bank were visualized using VMD 1.9.3.

\section{Homology modelling}

The homology model of Oleiagrimonas soli protease-avidin fusion protein was generated with Modeller 9.25 [74]. Swine pepsin (PDB ID: 4PEP; [75]) was used as a template for the protease domain, and streptavidin (PDB ID: $3 R Y 2$; [76]) for the avidin domain.

\section{Pairwise similarity and identity}

Pairwise sequence identity and pairwise sequence similarity were calculated using MatGAT 2.0 program (Matrix Global Alignment Tool) [77].

\section{Signal peptide prediction}

The presence of signal peptide was predicted using SignalP 5.0 [78]. 


\section{Sequence logos}

The sequence logos shown in Fig. 3f were built using ggseqlogo package in $\mathrm{R}$ [79]. The logos were manually curated to show only residues with occurrence above $20 \%$.

\section{Abbreviations}

MSA: Multiple sequence alignment; ML: Maximum likelihood; JTT: Jones-Taylor-Thornton; NJ: Neighbour-joining; NNI: Nearest-Neighbour-Interchange; GO: Gene Ontology.

\section{Supplementary Information}

The online version contains supplementary material available at https://doi. org/10.1186/s12862-021-01784-y.

Additional file 1: Table S1. Representative bacterial avidins. Table S2. Most significantly enriched pathways among the genes in direct vicinity of avidin gene. Table S3. Prediction of the structure-function of extended avidins. Table S4. Pairwise identities for the representative avidin sequences.

Additional file 2. Bacterial avidin sequences in FASTA format.

\section{Acknowledgements}

We acknowledge the long-term infrastructure support from Biocenter Finland and computational resources provided by CSC - IT Center for Science Ltd.

\section{Authors' contributions}

OHL, TPK, AS and VPH participated to the conception and design of the study. $\mathrm{OHL}, \mathrm{TPK}, \mathrm{SK}, \mathrm{AN}, \mathrm{AS}$ and VPH analyzed the data, OHL, TPK, SK, AS and VPH wrote the article. TPK, AN and SK contributed significantly to bioinformatics analysis and visualized the data. All authors read and approved the final manuscript.

\section{Funding}

The research has been supported financially by Grants from the Academy of Finland (Grant no. 290506 and 331946).

\section{Availability of data and materials}

The datasets used and/or analysed during the current study are available from the corresponding author on reasonable request.

\section{Declarations}

Ethics approval and consent to participate

Not applicable.

\section{Consent for publication}

Not applicable.

\section{Competing interests}

The authors declare that they have no competing interests.

\section{Author details}

${ }^{1}$ Faculty of Medicine and Health Technology, Tampere University, Tampere, Finland. ${ }^{2}$ Horticulture Technologies, Natural Resources Institute Finland, Turku, Finland. ${ }^{3}$ Fimlab Laboratories, Tampere, Finland.

Received: 15 November 2020 Accepted: 30 March 2021

Published online: 09 April 2021

\section{References}

1. Eakin RE, Mckinley WA, Williams RJ. Egg-white injury in chicks and its relationship to a deficiency of vitamin H (biotin). Science (80-). 1940;92:2245. https://doi.org/10.1126/science.92.2384.224.

2. Green NM. Avidin. 4. Stability at extremes of Ph and dissociation into subunits by guanidine hydrochloride. Biochem J. 1963;89:609-20.

3. Laitinen $\mathrm{OH}$, Nordlund $\mathrm{HR}$, Hytönen VP, Kulomaa MS. Brave new (strept) avidins in biotechnology. Trends Biotechnol. 2007. https://doi.org/10. 1016/j.tibtech.2007.04.001.

4. Laitinen $\mathrm{OH}$, Airenne KJ, Räty JK, Wirth T, Ylä-Herttuala S. Avidin fusion protein strategies in targeted drug and gene delivery. Lett Drug Des Discov. 2005;2:124. https://doi.org/10.2174/1570180053175197.

5. Tausig F, Wolf FJ. Streptavidin—a substance with avidin-like properties produced by microorganisms. Biochem Biophys Res Commun. 1964;14:205-9. https://doi.org/10.1016/0006-291x(64)90436-X.

6. Niskanen EA, Hytönen VP, Grapputo A, Nordlund HR, Kulomaa MS, Laitinen $\mathrm{OH}$. Chicken genome analysis reveals novel genes encoding biotin-binding proteins related to avidin family. BMC Genomics. 2005. https://doi.org/10.1186/1471-2164-6-41.

7. Ahlroth MK, Grapputo A, Laitinen $\mathrm{OH}$, Kulomaa MS. Sequence features and evolutionary mechanisms in the chicken avidin gene family. Biochem Biophys Res Commun. 2001;285:734-41. https://doi.org/10. 1006/bbrc.2001.5163.

8. Laitinen $\mathrm{OH}$, Hytönen VP, Ahlroth MK, Pentikäinen OT, Gallagher C, Nordlund $\mathrm{HR}$, et al. Chicken avidin-related proteins show altered biotin-binding and physico-chemical properties as compared with avidin. Biochem J. 2002;363:609. https://doi.org/10.1042/0264-6021: 3630609

9. Hytönen VP, Määttä JAE, Niskanen EA, Huuskonen J, Helttunen KJ, Halling KK, et al. Structure and characterization of a novel chicken biotin-binding protein A (BBP-A). BMC Struct Biol. 2007;7:8. https://doi. org/10.1186/1472-6807-7-8.

10. Hertz R, Sebrell WH. Occurrence of avidin in the oviduct and secretions of the genital tract of several species. Science. 1942;96:257. https://doi. org/10.1126/science.96.2489.257.

11. Botte V, Granata G. Induction of avidin synthesis by RNA obtained from lizard oviducts. J Endocrinol. 1977;73:535-6. https://doi.org/10.1677/ joe.0.0730535.

12. Hytönen VP, Laitinen $\mathrm{OH}$, Grapputo A, Kettunen A, Savolainen J, Kalkkinen N, et al. Characterization of poultry egg-white avidins and their potential as a tool in pretargeting cancer treatment. Biochem J. 2003;372:519-225. https://doi.org/10.1042/BJ20021531.

13. Bayer EA, Kulik T, Adar R, Wilchek M. Close similarity among streptavidin-like, biotin-binding proteins from Streptomyces. Biochim Biophys Acta. 1995;1263:60-6. https://doi.org/10.1016/0167-4781(95)00077-t.

14. Tuohimaa P, Joensuu T, Isola J, Keinänen R, Kunnas T, Niemelä $A$, et al. Development of progestin-specific response in the chicken oviduct. Int J Dev Biol. 1989;33:125-34.

15. Korpela JK, Elo HA, Tuohimaa PJ. Avidin induction by estrogen and progesterone in the immature oviduct of chicken, Japanese quail, duck, and gull. Gen Comp Endocrinol. 1981;44:230-2. https://doi.org/ 10.1016/0016-6480(81)90253-7.

16. Korpela J, Kulomaa M, Tuohimaa P, Vaheri A. Induction of avidin in chickens infected with the acute leukemia virus OK 10. Int J Cancer. 1982:30:461-4. https://doi.org/10.1002/ijc.2910300412.

17. Kunnas TA, Wallén MJ, Kulomaa MS. Induction of chicken avidin and related mRNAs after bacterial infection. Biochim Biophys Acta. 1993;1216:441-5. https://doi.org/10.1016/0167-4781(93)90012-3.

18. Shira EB, Friedman A. Innate immune functions of avian intestinal epithelial cells: response to bacterial stimuli and localization of responding cells in the developing avian digestive tract. PLOS ONE. 2018;13:e0200393. https://doi.org/10.1371/journal.pone.0200393.

19. Guo X, Xin J, Wang P, Du X, Ji G, Gao Z, et al. Functional characterization of avidins in amphioxus Branchiostoma japonicum: evidence for a dual role in biotin-binding and immune response. Dev Comp Immunol. 2017;70:106-18. https://doi.org/10.1016/j.dci.2017.01.006.

20. Yoza K-I, Imamura T, Kramer KJ, Morgan TD, Nakamura S, Akiyama K, et al. Avidin expressed in transgenic rice confers resistance to the stored-product insect pests Tribolium confusum and Sitotroga cerealella Biosci Biotechnol Biochem. 2005;69:966-71. https://doi.org/10.1271/ bbb.69.966. 
21. Christeller JT, Malone LA, Todd JH, Marshall RM, Burgess EPJ, Philip BA. Distribution and residual activity of two insecticidal proteins, avidin and aprotinin, expressed in transgenic tobacco plants, in the bodies and frass of Spodoptera litura larvae following feeding. J Insect Physiol. 2005;51:1117-26. https://doi.org/10.1016/j.jinsphys.2005.05.009.

22. Sinkkonen $A$, Laitinen $\mathrm{OH}$, Leppiniemi J, Vauramo S, Hytönen VP, Setälä $\mathrm{H}$. Positive association between biotin and the abundance of rootfeeding nematodes. Soil Biol Biochem. 2014;73:93-5. https://doi.org/ 10.1016/j.soilbio.2014.02.002

23. Takakura Y, Tsunashima M, Suzuki J, Usami S, Kakuta Y, Okino N, et al. Tamavidins-novel avidin-like biotin-binding proteins from the Tamogitake mushroom. FEBS J. 2009;276:1383-97. https://doi.org/10. 1111/j.1742-4658.2009.06879.x.

24. Mock DM, Mock NI, Stewart CW, LaBorde JB, Hansen DK. Marginal biotin deficiency is teratogenic in ICR mice. J Nutr. 2003;133:2519-25. https://doi.org/10.1093/jn/133.8.2519.

25. Taskinen B, Zmurko J, Ojanen M, Kukkurainen S, Parthiban M, Määttä JAE, et al. Zebavidin —an avidin-like protein from zebrafish. PLoS ONE. 2013;8:e77207. https://doi.org/10.1371/journal.pone.0077207.

26. Bowien B, Schlegel HG. Physiology and biochemistry of aerobic hydrogen-oxidizing bacteria. Annu Rev Microbiol. 1981;35:405-52. https://doi. org/10.1146/annurev.mi.35.100181.002201.

27. Helppolainen SH, Nurminen KP, Määttä JAE, Halling KK, Slotte JP, Huhtala T, et al. Rhizavidin from Rhizobium etli: the first natural dimer in the avidin protein family. Biochem J. 2007;405:397-405. https://doi.org/10.1042/ BJ20070076.

28. Leppiniemi J, Meir A, Kahkonen N, Kukkurainen S, Maatta JA, Ojanen M, et al. The highly dynamic oligomeric structure of bradavidin II is unique among avidin proteins. Protein Sci. 2013;22:980-94. https://doi.org/10. 1002/pro.2281.

29. Laitinen OH, Hytönen VP, Nordlund HR, Kulomaa MS. Genetically engineered avidins and streptavidins. Cell Mol Life Sci. 2006;63:2992-3017. https://doi.org/10.1007/s00018-006-6288-z.

30. Chilkoti A, Tan PH, Stayton PS. Site-directed mutagenesis studies of the high-affinity streptavidin-biotin complex: contributions of tryptophan residues 79, 108, and 120. Proc Natl Acad Sci USA. 1995;92:1754-8. https://doi.org/10.1073/pnas.92.5.1754.

31. Laitinen OH, Airenne KJ, Marttila AT, KulikT, Porkka E, Bayer EA, et al. Mutation of a critical tryptophan to lysine in avidin or streptavidin may explain why sea urchin fibropellin adopts an avidin-like domain. FEBS Lett. 1999;461:52-8. https://doi.org/10.1016/S0014-5793(99)01423-4.

32. Freitag S, Le Trong I, Chilkoti A, Klumb LA, Stayton PS, Stenkamp RE. Structural studies of binding site tryptophan mutants in the high-affinity streptavidin-biotin complex. J Mol Biol. 1998;279:211-21. https://doi.org/ 10.1006/jmbi.1998.1735

33. Marttila AT, Hytönen VP, Laitinen OH, Bayer EA, Wilchek M, Kulomaa MS. Mutation of the important Tyr-33 residue of chicken avidin: functional and structural consequences. Biochem J. 2003;369:249-54. https://doi. org/10.1042/BJ20020886.

34. Hunter S, Apweiler R, Attwood TK, Bairoch A, Bateman A, Binns D, et al. InterPro: the integrative protein signature database. Nucleic Acids Res. 2009;37:D211-5. https://doi.org/10.1093/nar/gkn785.

35. Hill J, Phylip LH. Bacterial aspartic proteinases. FEBS Lett. 1997:409:357-60. https://doi.org/10.1016/S0014-5793(97)00547-4.

36. Wu WJ, Zhao JX, Chen GJ, Du ZJ. Description of Ancylomarinasubtilis gen. nov., sp. nov., isolated from coastal sediment, proposal of Marinilabiliales ord. nov. and transfer of Marinilabiliaceae, Prolixibacteraceae and Marinifilaceae to the order Marinilabiliales. Int J Syst Evol Microbiol. 2016;66:4243-9. https://doi.org/10.1099/ijsem.0.001342.

37. Vandieken V, Marshall IPG, Niemann H, Engelen B, Cypionka H. Labilibaculum manganireducens gen. nov., sp. nov. and Labilibaculumfiliforme sp. nov., novel bacteroidetes isolated from subsurface sediments of the Baltic sea. Front Microbiol. 2018. https://doi.org/10.3389/fmicb.2017.02614.

38. Ji-Min $\mathrm{P}$, Jung-Hoon Y. Ancylomarinasalipaludis sp. nov., isolated from a salt marsh. Int J Syst Evol Microbiol. 2019;69:2750-4. https://doi.org/10. 1099/ijsem.0.003553.

39. Watanabe M, Kojima H, Fukui M. Labilibaculum antarcticum sp. nov., a novel facultative anaerobic, psychrotorelant bacterium isolated from marine sediment of Antarctica. Antonie van Leeuwenhoek Int J Gen Mol Microbiol. 2020;113:349-55. https://doi.org/10.1007/ s10482-019-01345-w.
40. Yadav S, Villanueva L, Bale N, Koenen M, Hopmans EC, Damsté JSS. Physiological, chemotaxonomic and genomic characterization of two novel piezotolerant bacteria of the family Marinifilaceae isolated from sulfidic waters of the Black Sea. Syst Appl Microbiol. 2020;43:126122. https://doi. org/10.1016/j.syapm.2020.126122.

41. Nedashkovskaya OI, Kim SB, Lysenko AM, Frolova GM, Mikhailov VV, Lee KH, et al. Description of Aquimarina muelleri gen. nov., sp. nov., and proposal of the reclassification of [Cytophaga] latercula Lewin 1969 as Stanierellalatercula gen. nov., comb. nov. Int J Syst Evol Microbiol. 2005;55:225-9. https://doi.org/10.1099/ijs.0.63349-0.

42. Bae SS, Kwon KK, Yang SH, Lee HS, Kim SJ, Lee JH. Flagellimonaseckloniae gen. nov., sp. nov., a mesophilic marine bacterium of the family Flavobacteriaceae, isolated from the rhizosphere of Ecklonia kurome. Int J Syst Evol Microbiol. 2007;57:1050-4. https://doi.org/10.1099/ijs.0.64565-0.

43. Hahnke RL, Meier-Kolthoff JP, García-López M, Mukherjee S, Huntemann M, Ivanova NN, et al. Genome-based taxonomic classification of Bacteroidetes. Front Microbiol. 2016. https://doi.org/10.3389/fmicb.2016.02003.

44. Alain K, Tindall BJ, Catala P, Intertaglia L, Lebaron P. Ekhidnalutea gen. nov., sp. nov., a member of the phylum Bacteroidetes isolated from the South East Pacific Ocean. Int J Syst Evol Microbiol. 2010;60:2972-8. https://doi. org/10.1099/ijs.0.018804-0.

45. Choi A, Oh HM, Yang SJ, Cho JC. Kordia periserrulae sp. nov., isolated from a marine polychaete periserrula leucophryna, and emended description of the genus Kordia. Int J Syst Evol Microbiol. 2011;61:864-9. https://doi. org/10.1099/ijs.0.022764-0.

46. Ruvira MA, Lucena T, Pujalte MJ, Arahal DR, Macián MC. Marinifilumflexuosum sp. nov., a new Bacteroidetes isolated from coastal Mediterranean Sea water and emended description of the genus Marinifilum Na et al., 2009. Syst Appl Microbiol. 2013;36:155-9. https://doi.org/10.1016/j. syapm.2012.12.003.

47. Lau SCK, Tsoi MMY, Li X, Plakhotnikova I, Dobretsov S, Wu M, et al. Description of Fabibacter halotolerans gen. nov., sp. nov. and Roseivirgaspongicola sp. nov., and reclassification of [Marinicola] seohaensis as Roseivirgaseohaensis comb. nov. Int J Syst Evol Microbiol. 2006;56:105965. https://doi.org/10.1099/ijs.0.64104-0.

48. Lee DW, Lee JE, Lee SD. Chitinophaga rupis sp. nov, isolated from soil. Int J Syst Evol Microbiol. 2009;59:2830-3. https://doi.org/10.1099/ijs.0. 011163-0.

49. Yanai I. An avidin-like domain that does not bind biotin is adopted for oligomerization by the extracellular mosaic protein fibropellin. Protein Sci. 2005;14:417-23. https://doi.org/10.1110/ps.04898705.

50. Howarth M, Chinnapen DF, Gerrow K, Dorrestein PC, Grandy MR, Kelleher $\mathrm{NL}$, et al. A monovalent streptavidin with a single femtomolar biotin binding site. Nat Methods. 2006;3:267-73. https://doi.org/10.1038/nmeth 861.

51. Nordlund HR, Hytönen $V P$, Laitinen $\mathrm{OH}$, Uotila STH, Niskanen EA, Savolainen J, et al. Introduction of histidine residues into avidin subunit interfaces allows $\mathrm{pH}$-dependent regulation of quaternary structure and biotin binding. FEBS Lett. 2003;555:449-54. https://doi.org/10.1016/ S0014-5793(03)01302-4.

52. Laitinen $\mathrm{OH}$, Nordlund HR, Hytönen VP, Uotila STH, Marttila AT, Savolainen $J$, et al. Rational design of an active avidin monomer. J Biol Chem. 2003:278:4010-4 https://doi.org/10.1074/jbc.M205844200.

53. Meir A, Helppolainen SH, Podoly E, Nordlund HR, Hytönen VP, Määttä $J A$, et al. Crystal structure of rhizavidin: insights into the enigmatic highaffinity interaction of an innate biotin-binding protein dimer. J Mol Biol. 2009;386:379-90. https://doi.org/10.1016/j.jmb.2008.11.061.

54. Avraham O, Meir A, Fish A, Bayer EA, Livnah O. Hoefavidin: a dimeric bacterial avidin with a C-terminal binding tail. J Struct Biol. 2015;191:139-48. https://doi.org/10.1016/j.jsb.2015.06.020.

55. Agrawal N, Määttä JAE, Kulomaa MS, Hytönen VP, Johnson MS, Airenne TT. Structural characterization of core-bradavidin in complex with biotin. PLoS ONE. 2017. https://doi.org/10.1371/journal.pone.0176086.

56. Stẹpkowski T, Moulin L, Krzyzańska A, Mclnnes A, Law IJ, Howieson J. European origin of bradyrhizobium populations infecting lupins and serradella in soils of Western Australia and South Africa. Appl Environ Microbiol. 2005;71:7041-52. https://doi.org/10.1128/AEM.71.11.70417052.2005.

57. Holmes PM, Cowling RM. The effects of invasion by Acacia saligna on the guild structure and regeneration capabilities of South African Fynbos Shrublands. J Appl Ecol. 1997;34:317. https://doi.org/10.2307/2404879. 
58. Luque GM, Bellard C, Bertelsmeier C, Bonnaud E, Genovesi P, Simberloff D, et al. The 100th of the world's worst invasive alien species. Biol Invasions. 2014;16:981-5. https://doi.org/10.1007/s10530-013-0561-5.

59. Lafay B, Burdon JJ. Molecular diversity of rhizobia nodulating the invasive legume Cytisus scoparius in Australia. J Appl Microbiol. 2006;100:1228-38. https://doi.org/10.1111/j.1365-2672.2006.02902.x.

60. Mumba M, Thompson JR. Hydrological and ecological impacts of dams on the Kafue Flats floodplain system, southern Zambia. Phys Chem Earth. 2005:30:442-7. https://doi.org/10.1016/j.pce.2005.06.009.

61. Barrett CF, Parker MA. Coexistence of Burkholderia, Cupriavidus, and Rhizobium sp. nodule bacteria on two Mimosa spp. in Costa Rica. Appl Environ Microbiol. 2006;72:1198-206. https://doi.org/10.1128/AEM.72.2. 1198-1206.2006.

62. Stępkowski T, Hughes CE, Law IJ, Markiewicz Ł, Gurda D, Chlebicka A, et al. Diversification of lupine Bradyrhizobium strains: evidence from nodulation gene trees. Appl Environ Microbiol. 2007;73:3254-64. https://doi.org/ 10.1128/AEM.02125-06.

63. Parker MA, Wurtz AK, Paynter Q. Nodule symbiosis of invasive Mimosa pigra in Australia and in ancestral habitats: a comparative analysis. Biol Invasions. 2007:9:127-38. https://doi.org/10.1007/s10530-006-0009-2.

64. Weir BS, Turner SJ, Silvester WB, Park D-C, Young JM. Unexpectedly diverse Mesorhizobium strains and Rhizobiumleguminosarum nodulate native legume genera of New Zealand, while introduced legume weeds are nodulated by Bradyrhizobium species. Appl Environ Microbiol. 2004;70:5980-7. https://doi.org/10.1128/AEM.70.10.5980-5987.2004.

65. Bateman A, Martin MJ, O'Donovan C, Magrane M, Alpi E, Antunes R, et al. UniProt: the universal protein knowledgebase. Nucleic Acids Res. 2017:45:D158-69. https://doi.org/10.1093/nar/gkw1099.

66. Przybylski D, Rost B. Powerful fusion: PSI-BLAST and consensus sequences. Bioinformatics. 2008;24:1987-93. https://doi.org/10.1093/ bioinformatics/btn384.

67. Mashima J, Kodama Y, Fujisawa T, Katayama T, Okuda Y, Kaminuma E, et al. DNA Data Bank of Japan. Nucleic Acids Res. 2017:45:D25-31. https://doi. org/10.1093/nar/gkw1001.

68. Benson DA, Clark K, Karsch-Mizrachi I, Lipman DJ, Ostell J, Sayers EW. GenBank. Nucleic Acids Res. 2014;42:D32-7. https://doi.org/10.1093/nar/ gkt1030.

69. Kanz C, Aldebert P, Althorpe N, Baker W, Baldwin A, Bates K, et al. The EMBL nucleotide sequence database. Nucleic Acids Res. 2005;33:D29-33. https://doi.org/10.1093/nar/gki098.

70. Notredame C, Higgins DG, Heringa J. T-coffee: a novel method for fast and accurate multiple sequence alignment. J Mol Biol. 2000;302:205-17. https://doi.org/10.1006/jmbi.2000.4042.

71. Larsson A. Aliview: a fast and lightweight alignment viewer and editor for large datasets. Bioinformatics. 2014;30:3276-8. https://doi.org/10.1093/ bioinformatics/btu531.

72. Edgar RC. MUSCLE: Multiple sequence alignment with high accuracy and high throughput. Nucleic Acids Res. 2004;32:1792-7. https://doi.org/10 1093/nar/gkh340.

73. Tamura K, Stecher G, Peterson D, Filipski A, Kumar S. MEGA6: molecular evolutionary genetics analysis version 6.0. Mol Biol Evol. 2013;30:2725-9. https://doi.org/10.1093/molbev/mst197.

74. Sali A, Blundell TL. Comparative protein modelling by satisfaction of spatial restraints. J Mol Biol. 1993;234:779-815. https://doi.org/10.1006/ jmbi.1993.1626.
75. Sielecki AR, Fedorov AA, Boodhoo A, Andreeva NS, James MN. Molecular and crystal structures of monoclinic porcine pepsin refined at $1.8 \mathrm{~A}$ resolution. J Mol Biol. 1990;214:143-70. https://doi.org/10.1016/00222836(90)90153-D.

76. Le Trong I, Wang Z, Hyre DE, Lybrand TP, Stayton PS, Stenkamp RE. Streptavidin and its biotin complex at atomic resolution. Acta Crystallogr D Biol Crystallogr. 2011;67:813-21. https://doi.org/10.1107/S090744491 1027806.

77. Campanella JJ, Bitincka L, Smalley J. MatGAT: an application that generates similarity/identity matrices using protein or DNA sequences. BMC Bioinform. 2003;4:29. https://doi.org/10.1186/1471-2105-4-29.

78. Petersen TN, Brunak S, von Heijne G, Nielsen H. SignalP 4.0: discriminating signal peptides from transmembrane regions. Nat Methods. 2011;8:7856. https://doi.org/10.1038/nmeth. 1701.

79. Wagih O. ggseqlogo: a versatile $\mathrm{R}$ package for drawing sequence logos. Bioinformatics. 2017;33:3645-7. https://doi.org/10.1093/bioinformatics/ btx469.

80. Armougom F, Moretti S, Poirot O, Audic S, Dumas P, Schaeli B, Keduas V, Notredame C. Expresso: automatic incorporation of structural information in multiple sequence alignments using 3D-Coffee. Nucleic Acids Res. 2006;34(Web Server issue):W604-8. https://doi.org/10.1093/nar/gkl092.

81. Di Tommaso P, Moretti S, Xenarios I, Orobitg M, Montanyola A, Chang JM, Taly JF, Notredame C. T-Coffee: a web server for the multiple sequence alignment of protein and RNA sequences using structural information and homology extension. Nucleic Acids Res. 2011;39(Web Server issue):W13-7. https://doi.org/10.1093/nar/gkr245.

82. Langholm Jensen J, Mølgaard A, Navarro Poulsen JC, Harboe MK, Simonsen JB, Lorentzen AM, Hjernø K, van den Brink JM, Qvist KB, Larsen S. Camel and bovine chymosin: the relationship between their structures and cheese-making properties. Acta Crystallogr D Biol Crystallogr. 2013:69:901-13. https://doi.org/10.1107/S0907444913003260.

83. Hánová I, Brynda J, Houštecká R, Alam N, Sojka D, Kopáček P, Marešová L, Vondrášek J, Horn M, Schueler-Furman O, Mareš M. Novel structural mechanism of allosteric regulation of aspartic peptidases via an evolutionarily conserved exosite. Cell Chem Biol. 2018;25:318-29. https://doi. org/10.1016/j.chembiol.2018.01.001

84. Suguna K, Padlan EA, Smith CW, Carlson WD, Davies DR. Binding of a reduced peptide inhibitor to the aspartic proteinase from Rhizopuschinensis: implications for a mechanism of action. Proc Natl Acad Sci USA. 1987;84:7009-13. https://doi.org/10.1073/pnas.84.20.7009.

85. Repo S, Paldanius TA, Hytönen VP, Nyholm TK, Halling KK, Huuskonen J, Pentikäinen OT, Rissanen K Slotte JP, Airenne TT, Salminen TA, Kulomaa MS, Johnson MS. Binding properties of HABA-type azo derivatives to avidin and avidin-related protein 4. Chem Biol. 2006;13:1029-39. https:// doi.org/10.1016/j.chembiol.2006.08.006.

\section{Publisher's Note}

Springer Nature remains neutral with regard to jurisdictional claims in published maps and institutional affiliations.

Ready to submit your research? Choose BMC and benefit from

- fast, convenient online submission

- thorough peer review by experienced researchers in your field

- rapid publication on acceptance

- support for research data, including large and complex data types

- gold Open Access which fosters wider collaboration and increased citations

- maximum visibility for your research: over $100 \mathrm{M}$ website views per year

At BMC, research is always in progress.

Learn more biomedcentral.com/submissions 